\title{
Physico-Chemical Analysis of Surface and Groundwater around Talcher Coal Field, District Angul, Odisha, India
}

\author{
Madhusmita Sahoo, Malaya Ranjan Mahananda*, Prabhati Seth \\ Department of Environmental Sciences, Sambalpur University, Sambalpur, India \\ Email: madhusmita.mitali1991@gmail.com, malaya_env@rediffmail.com, prabha0702@gmail.com
}

Received 8 December 2015; accepted 3 February 2016; published 6 February 2016

Copyright @ 2016 by authors and Scientific Research Publishing Inc.

This work is licensed under the Creative Commons Attribution International License (CC BY). http://creativecommons.org/licenses/by/4.0/

(c) (i) Open Access

\section{Abstract}

The present study deals with the water quality of Talcher Area. Sample was collected from Ghats of river Brahmani, tube well and tap water of different colonies in Monsoon and in Post Monsoon. The collected sample was analysed in P.G Department of Environmental Sciences, Sambalpur University. The parameters studied were DO, pH, Conductivity, Temperature, Sodium, Potassium, Dissolve Oxygen, Total Solid, Chloride, Alkalinity, Hardness, Sulphate, Chemical Oxygen Demand, Nitrate, Phosphate and Fluoride. Water quality index was calculated by using NSF water quality index. Analyzed data were compared with the standard IS: 2296 (Surface Water Quality Standard) and IS: 10500 (Drinking water Quality Standard). The maximum $\mathrm{pH}$ of $7.91 \pm 0.17$ was found at Jagannath Ghat. Maximum average conductivity was found as $559.28 \pm 8.92 \mu \mathrm{S} / \mathrm{cm}$ in tube well water of Jagannath colony and minimum was $90.66 \pm 1.15 \mu \mathrm{S} / \mathrm{cm}$ in Tarini Ghat. Temperature was maximum $28.5^{\circ} \mathrm{C} \pm 0.36^{\circ} \mathrm{C}$ in tube well water of C.W.S. Colony. The maximum Sodium, Potassium, Chloride, Alkalinity and Nitrate content was recorded as $12.37 \pm 1.23,95.9 \pm 7.75,541.66 \pm 2.84$ and $24.27 \pm 0.61 \mathrm{mg} / \mathrm{L}$ respectively in tube well water of Balanda colony. The high dissolved oxygen content was recorded as $7.92 \pm 0.34 \mathrm{mg} / \mathrm{L}$ in tap water of C.W.S. colony. Maximum hardness value was recorded as $326.69 \pm 5.30 \mathrm{mg} / \mathrm{L}$ in tube well water of C.W.S. colony. The high value of COD and Sulphate was recorded as $188 \pm 8$ and $132 \pm 5.43 \mathrm{mg} / \mathrm{L}$ in tube well water of Jagannath colony. Maximum Phosphate and Fluoride content was recorded as $423.27 \pm 2.59$ and $664.23 \pm$ $5.03 \mu \mathrm{g} / \mathrm{L}$ respectively in Paschimeswar Ghat. Statistical calculation was subjected to two-way ANOVA and Correlation coefficient.

\section{Keywords}

DO, Temperature, Chloride, Sulphate, Phosphate

\footnotetext{
${ }^{*}$ Corresponding author.
}

How to cite this paper: Sahoo, M., Mahananda, M.R. and Seth, P. (2016) Physico-Chemical Analysis of Surface and Groundwater around Talcher Coal Field, District Angul, Odisha, India. Journal of Geoscience and Environment Protection, 4, 26-37. http://dx.doi.org/10.4236/gep.2016.42004 


\section{Introduction}

Water is an essential constituent of all the animal and plant life. A river and its tributaries play an important role in industrial and social development. Growing population, accelerating industrialization and intensification of agriculture and also urbanization exert heavy pressure on our vast but limited water resources. Waste water from mining and other related industries is the most common source of water pollution and it is increasing day by day [1]. The effluents from mines and industries have a great deal of influence on the pollution of the water body; these effluents can alter the physical, chemical and biological nature of the receiving water body [2]. Municipal and industrial waste water discharge constitutes a constant polluting source, whereas surface runoff is seasonal phenomenon, largely affected by climate within the basin [3]. However the untreated/partially treated waste water may contain toxic compounds, discharge from industries, mining, domestic and commercial areas enter the surface water body they get dissolved or lie suspended in water or get deposited on the bed [4].

Brahmani river basin along Angul-Talcher region is based on heavy deposit of coal and other minerals. Coal mines and related industries spread over major urban and sub-urban areas of that region. Industrialisation is considered the trigger of development strategies due to its significant contribution to the economic growth and human welfare [5]. Availability of water and good infrastructure has to be conducive for industrialization in the study area. River and other streams are not far from the industries and contaminate continuously from point as well as non-point source. Waste generation due to the operation and expansion of mining and industrial activity in Angul-Talcher is going to be a serious negative impact on the water resource in the near future. This problem is persisting and cannot be ignored that it can have a serious long-term impact on water resource. The impact of effluent discharge from mining and other industries on water resources may range from minimal through to severe [6]. The mines of MCL, Aluminium smelter, NTPC's power plants etc. draw water for their use from the Brahmani and its tributaries and in return they release thousands of gallons of wastewater to the river, which contains obnoxious substances like SS, TDS, ash, oil \& grease, heavy metals, fluorides, phosphorus, ammonia, urea and acids. The fly ash generated during these power plant operations and ash ponds in the coalfield area also created environmental hazard particularly in water by increasing the suspended, dissolved and heavy metals concentration. Somewhere the water of river Brahmani including tributaries is not matching the prescribed limits of Indian Standard. The river water samples show that various physical and chemical parameters are not within the class "C” limits of Indian Standard [7].

\section{Objectives}

\subsection{Main Objective}

To study the water quality of Talcher area.

\subsection{Specific Objectives}

- To study the water quality of river Brahmani flowing through Talcher area.

- To study the water quality of communal Tube well found in Talcher area.

- To study the quality of supply water (Tap water) in different colonies of Talcher area for drinking purpose.

\section{Study Area}

Angul-Talcher Industrial complex of Odisha is situated at latitude $200^{\circ} 95^{\prime} \mathrm{N}$ to $210^{\circ} 10^{\prime} \mathrm{N}$ and longitude $840^{\circ} 55^{\prime} \mathrm{E}$ to $850^{\circ} 28^{\prime} \mathrm{E}, 139$ meter above sea level (MSL) and $150 \mathrm{~km}$ away from Bhubaneswar, the state capital of Odisha (Figure 1). It is a thickly populated area. This area is one of the largest coal belts of India. The two major rivers namely Mahanadi and Bramhani are flowing on the two sides of the study area. Taking the advantages of the location, vast coal deposits, water availability and the manpower, Mahanadi Coal Fields Ltd. (MCL) has developed a number of open cast and underground mines in this industrial complex. Besides, a good number of coal based Thermal Power Plants (National Thermal Power Corporation, Kaniha, National Thermal Power Station, Talcher, Captive Power Plant, NALCO, Angul), several heavy industries (National Aluminum Company, Angul, Heavy Water Project, Vikrampur, Bhushan Steel and Strips Ltd., Jindal Power and Steel Ltd., Silicon Steel, Nava Bharat Ferroalloys, Monet Ispat Ltd., Rungta Mines Ltd., etc.), coal washeries and a large number of ancillary medium and small scale industrial units have come up in the area in the last few decade. All these mining and industrial activities have caused significant degradation of environmental quality and now this area is considered 


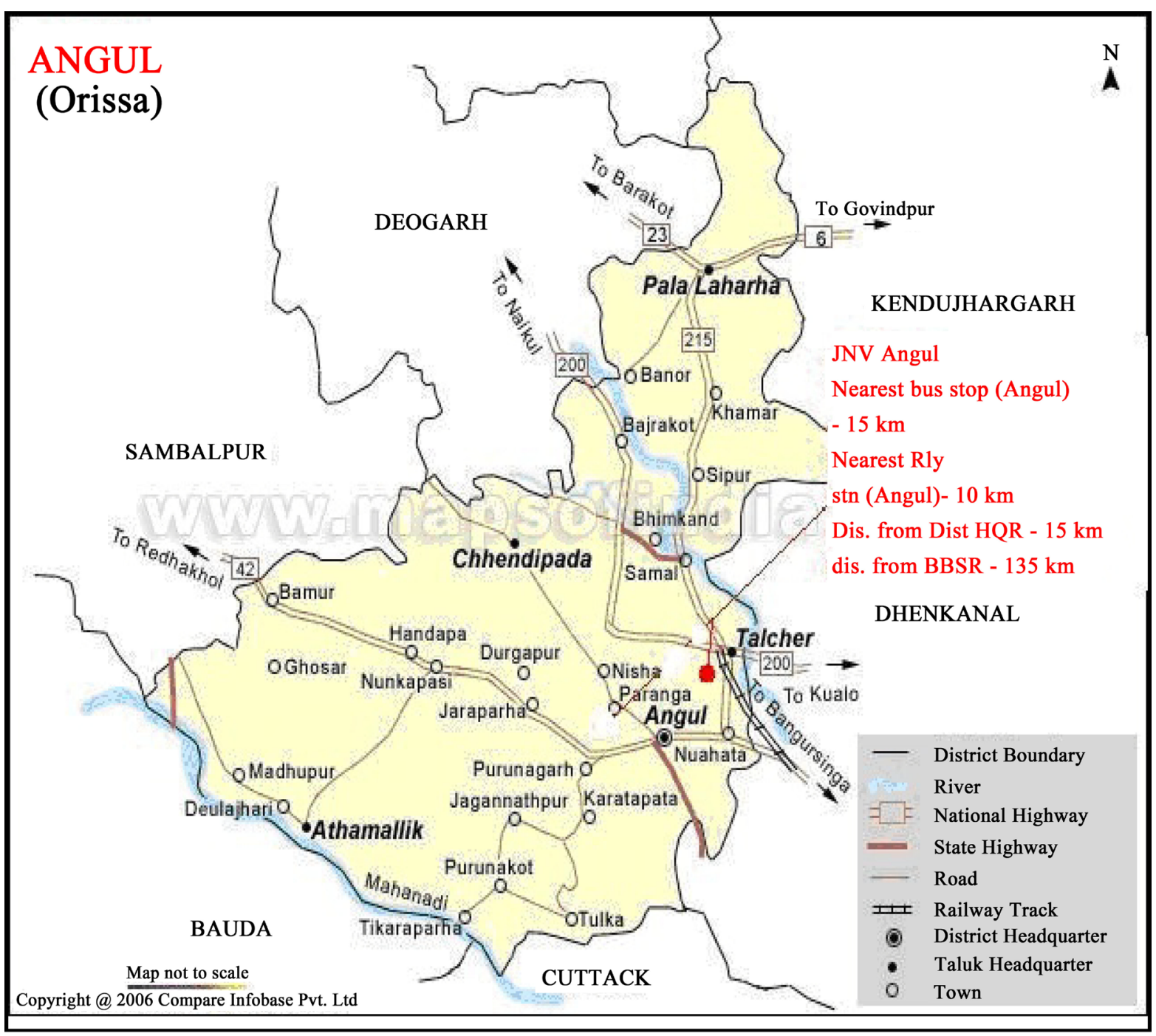

Figure 1. Map of Angul district.

as one among 24 hot spots of India. Though coal mines are not having any effluents discharged, the washout of mining areas and drain water from workshops \& townships ultimately goes to the river. The coal washeries coming up in the locality may add in future. In this way the river water gets polluted.

\section{Materials and Methods}

Sampling is the first essential step in accessing the quality of water. The present investigation is carried out during the Monsoon and Post Monsoon season of the year 2014. Water samples were collected in plastic bottles. After collection, the sample has been handled and preserved carefully to prevent any alternation in physical and chemical properties. Water samples were collected from three different sites of the river Brahmani, tube well and tap water of three different colonies. Before releasing of water to the locality area of Angul District, tap water was treated with Alum and Bleaching powder after passing through sand bed and Sabai grass. The three different sites of river Brahmani are Jagannath Ghat, Tarini Ghat and Pashimeswar Ghat and the three Colonies are C.W.S. Colony, Jagannath Colony and Balanda Colony (Figure 2). From 9 sites total 27 samples were collected for analysis and the mean values were considered.

In the present study $\mathrm{pH}$ has been measured soon after the collection of samples by a $\mathrm{pH}$ meter by electrometric method. Simultaneously the temperature is also measured by the systronic $\mathrm{pH}$ meter. Conductivity of the different samples has been measured using a conductivity meter by electrometric method. Sodium and potas- 


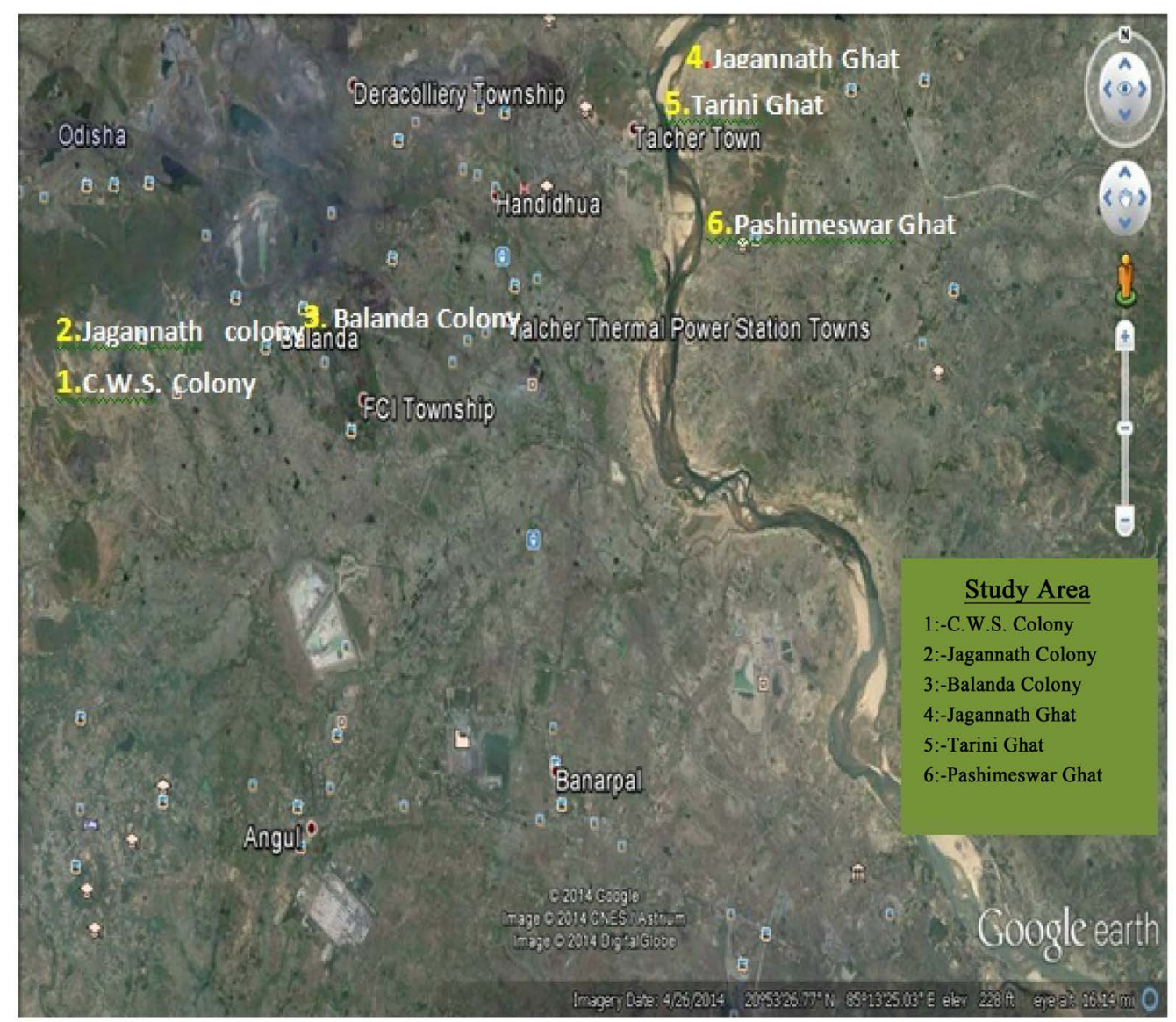

Figure 2. Google earth map of study area showing sampling locations.

sium was estimated by systronic flame photometer. Winkler iodometric method was used for the determination of dissolved oxygen in water samples. The analysis of the sample was done on the basis of standard methods suggested by the American Public Health Association. Total Solid content was determined by Gravimetric method. In the present study chloride content was determined by Argentometric method. Total hardness of the samples was analysed by titration with EDTA using Erichome black-T as an indicator.Total alkalinity and alkalinity due to carbonates, bicarbonates were estimated by titrating the sample with diluted $\mathrm{H}_{2} \mathrm{SO}_{4}$ using phenolphthalein as an indicator to $\mathrm{pH} 8.3$ and methyl orange as an indicator to $\mathrm{pH} 4.2$ and 5.4.The titrate value gives phenolphthalein alkalinity (PA) and the second one gives total alkalinity (TA). COD is determined by using reflux condenser, ferroin indicator and titrating the sample with ferrous ammonium sulphate. Nitrate and phosphate can be determined by spectrophotometric method. Determination of fluoride is done by SPADNS method.

\section{Results and Discussion}

The variation in physico-chemical characteristics of the River water, Tube well water and Tap water have been summarized in the Table 1 and Table 2. Analytical results revealed physicochemical characteristics of water samples from nine locations of study area in Monsoon and Post Monsoon period.

\section{1. $\mathrm{pH}$}

As compared to the river water, tap water \& tube well water, the maximum value of $\mathrm{pH}$ was found in Jagannath Ghat of river Brahmani i.e. $7.91 \pm 0.17$ during monsoon period which indicates the alkaline nature of water [8] and the minimum value was found in Pashimeswar Ghat of river Brahman i.e. $6.66 \pm 0.29$ in post monsoon (Table 1 \& Table 2). $\mathrm{pH}$ values are well within the range as compared to permissible limit of $\mathrm{pH}$ in drinking water which is within 6.5 to 8.5 as per IS: 2296. The water was alkaline in nature which could be due to solutes 


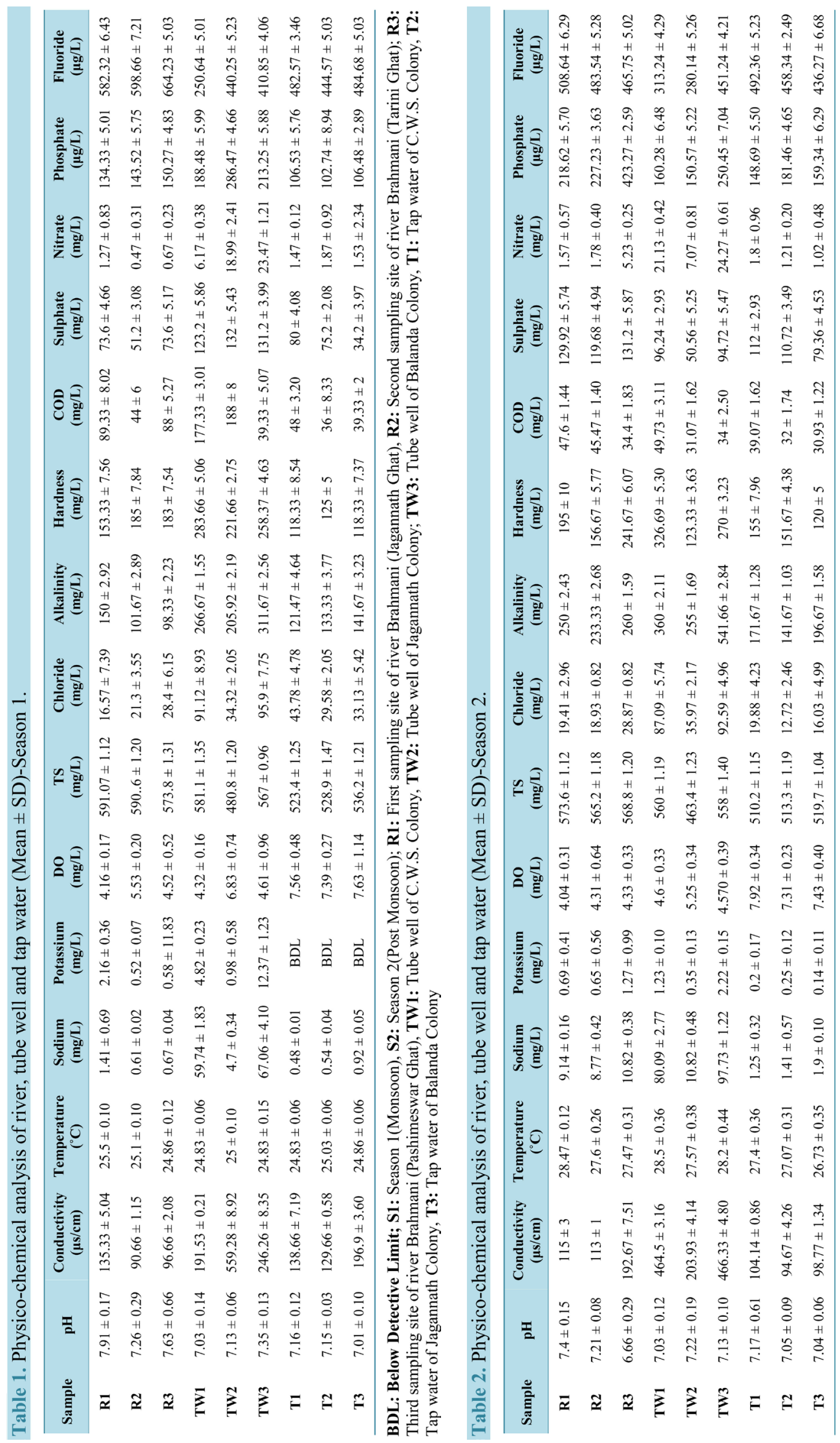


which may show a buffering action i.e. $\mathrm{H}^{+}$ions are compensated with $\mathrm{OH}^{-}$ions. Alkaline state of $\mathrm{pH}$ might be due to chemical buffering and release of bicarbonate and carbonate ions or salts [9]. All the samples have $\mathrm{pH}$ values below the prescribed values and could be classified as suitable for drinking purpose. The value showed a trend of increasing pattern from monsoon to summer (acidic and alkaline) with little seasonal variations [10]. The reduced rate of photosynthetic activities reduces the assimilation of carbon dioxide and bicarbonates which are ultimately responsible for increase in $\mathrm{pH}$ [11]. The $\mathrm{pH}$ value of river, tube well and tap water shows no significant difference $(\mathrm{Fc}=1.21<\mathrm{Ft}=0.39)$. Also $\mathrm{pH}$ values of season 1 and season 2 shows no significant difference when subjected to two-way ANOVA $(\mathrm{Fc}=2.74<\mathrm{Ft}=0.14)$.

\subsection{Conductivity}

Among river water, tap water and tube well water minimum conductivity was found in Tarini Ghat of River water i.e. $90.66 \pm 1.15 \mu \mathrm{S} / \mathrm{cm}$ in monsoon and maximum conductivity was found in tube well water of Jagannath colony i.e. $559.28 \pm 8.92 \mu \mathrm{S} / \mathrm{cm}$ in monsoon period. Values are slightly higher in monsoon than post monsoon season (Table 1 and Table 2). High conductivity attributed to the predominance of non leached substratum. Dilution of water during the monsoon season causes a decrease in electrical conductance of rain water [9]. The difference in conductivity value in river, tube well and tap water $(\mathrm{Fc}=1.60<\mathrm{Ft}=3.44)$ and Seasonal variation $(\mathrm{Fc}=0.01<\mathrm{Ft}=5.32)$ shows no significant difference.

\subsection{Temperature}

Temperature was found maximum in tube well water of C.W.S. colony i.e. $28.50^{\circ} \mathrm{C} \pm 0.36^{\circ} \mathrm{C}$ in Post Monsoon and minimum in tube well water of C.W.S. colony, Balanda colony and tap water of C.W.S. colony i.e. $24.83^{\circ} \mathrm{C}$ $\pm 0.06^{\circ} \mathrm{C}$. During the present investigation, no great difference was found between the temperature of the river water, tube well water and tap water and the temperature was between $24^{\circ} \mathrm{C}-28^{\circ} \mathrm{C}$ (Table 1 and Table 2). The maximum temperature was due to greater solar radiation, clear atmosphere and higher atmospheric temperature. During winter the temperature remain low due to cold low ambient temperature and shorter photo period [9]. Area wise temperature between river, tube well and tap water found no significant difference $(\mathrm{Fc}=1.52<\mathrm{Ft}=$ 3.44) but seasonal variation found highly significant $(\mathrm{Fc}=194.65>\mathrm{Ft}=5.32)$ subjected to two way ANOVA.

\subsection{Sodium}

Maximum sodium was found in tube well water of Balanda colony i.e. $97.73 \pm 1.22 \mathrm{mg} / \mathrm{L}$ during Post Monsoon due to high rate of mineralization in the sediments but minimum value was found in tap water of C.W.S. colony i.e. $0.48 \pm 0.01 \mathrm{mg} / \mathrm{L}$ as compare to river water can be explained on the basis of lower microbial activity [8]. Maximum sodium found in tube well water due to leaching of surface and underground deposits of salts (Table 1 \& Table 2). The addition of waste water containing soap solution and detergent from the surrounding slummy area are responsible for increasing sodium level in water bodies [9]. The sodium content between areas and seasons show significant difference when subjected to ANOVA [Areas $(\mathrm{Fc}=41.01>3.44)$, Seasons $(\mathrm{Fc}=8.12>$ 5.32)].

\subsection{Potassium}

Maximum potassium content was found in tube well water of Balanda colony i.e. $12.37 \pm 1.23 \mathrm{mg} / \mathrm{L}$ and minimum value was found in tap water of all the colonies in monsoon. In monsoon all the samples of tap water found as below detective level (Table 1 \& Table 2). Potassium remains mostly in solution without undergoing precipitation. The high value of potassium in tube well water in Balanda colony might be due to the presence of geochemical strata [8]. Subjected to two way ANOVA the seasonal variation and area wise variation in Potassium content of river, tube well and tap water shows no significant difference. Area $(\mathrm{Fc}=1.82<\mathrm{Ft}=3.44)$ and Season $(\mathrm{Fc}=1.9260931<\mathrm{Ft}=5.32)$.

\subsection{Dissolved Oxygen (D0)}

Maximum DO was found in tap water of C.W.S. colony during Post Monsoon period i.e. $7.92 \pm 0.34 \mathrm{mg} / \mathrm{L}$ but minimum DO was found in river water in Jagannath Ghat during Post Monsoon i.e. $4.04 \pm 0.31 \mathrm{mg} / \mathrm{L}$ (Table 1 \& Table 2). The DO value ranges within the permissible limit for drinking water as per IS: 2296. Dissolve oxy- 
gen increases due to the dissolve of oxygen during the period of photosynthesis. In the present study DO content of water sample ranged from 4.04 to $7.92 \mathrm{mg} / \mathrm{L}$. As DO level falls; undesirable odours, tastes and colours reduce the acceptability of water. The lowest DO value indicates not good healthy condition for the community [12]. High temperature and addition of sewage and other waste might be responsible for the low value of DO [9]. Significant changes of DO were observed due to aeration, organic matter elimination of addition from sediments, algal activities [13]. The water quality at downstream was comparatively more disturbed than the upstream as well as dam reservoir due to release of domestic sewages, washing of motor vehicles, bank side abuses by people, surface run off and agricultural tail water to river system [14]. The dissolve oxygen content of river, tube well and tap water shows significant difference $(\mathrm{Fc}=20.91>\mathrm{Ft}=3.44)$ and the seasonal variation shows no significant difference $(\mathrm{Fc}=2.02<\mathrm{Ft}=5.32)$.

\subsection{Total Solids (TS)}

Among river water, tube well water and tap water maximum total solid was found in river water of Jagannath Ghat in Monsoon i.e. $591.07 \pm 1.12 \mathrm{mg} / \mathrm{L}$ and minimum total solid was found in tube well water of Jagannath colony i.e. $463.4 \pm 1.23 \mathrm{mg} / \mathrm{L}$ (Table $1 \&$ Table 2). The total suspended solids are composed of carbonates, bicarbonates, chlorides, phosphates and nitrates of calcium, magnesium, sodium, potassium, manganese, organic matter, salt and other particles. The effect of presence of total suspended solids is the turbidity may be due to silt and organic matter. Due to contamination of domestic waste water, garbage, fertilizer in the natural surface water the TS was reported to be high [9]. During winter and summer, concentration of dissolved solids was reported to be more (54.0\% - 74.0\%) in comparison to the suspended residue [15]. Significant difference found in total solids between the areas and the seasons. Area $(\mathrm{Fc}=150.22>\mathrm{Ft}=3.44)$, Season $(\mathrm{Fc}=59.52>$ $\mathrm{Ft}=5.32)$.

\subsection{Chloride}

The maximum value of chloride content was recorded in tube well water of Balanda colony in Monsoon i.e. $95.90 \pm 7.75 \mathrm{mg} / \mathrm{L}$ and minimum value was recorded in tap water of Balanda colony in post monsoon i.e. 16.03 $\pm 4.99 \mathrm{mg} / \mathrm{L}$ (Table $1 \&$ Table 2). The chlorine content of water samples may decrease rapidly, particularly at warm temperatures. Exposure to strong light or agitation will accelerate the rate of loss of chlorine, so maximum chloride was found in tube well water where as less chloride found in tap \& river water. The high chloride concentration of water may be due to high rate of evaporation or due to organic waste of animal origin [9]. The higher content of Chloride in pond may be due to animal origin like human faeces and sewage inflow [16]. In uncontaminated water which is not flowing from sediments, the quality of chloride present is ordinary quantity [17]. The high concentration of chloride may be due to the uses of inorganic fertilizer, land fill leachates, septic tank effluent and industrial and irrigation drainage [18]. Significantly the river, tube well and tap water differ highly from each other but seasonally non significant. Area $(\mathrm{Fc}=37.24>\mathrm{Ft}=3.43)$, Season $(\mathrm{Fc}=4.60<\mathrm{Ft}=$ 5.31).

\subsection{Alkalinity}

Alkalinity was found minimum in Pashimeswar Ghat of river Brahmani in Monsoon i.e. $98.33 \pm 2.23 \mathrm{mg} / \mathrm{L}$ and maximum in tube well water of Balanda colony in Post Monsoon i.e. $541.67 \pm 2.84 \mathrm{mg} / \mathrm{L}$ (Table 1 \& Table 2). The alkalinity of water is caused mainly due to $\mathrm{OH}, \mathrm{CO}_{3}, \mathrm{HCO}_{3}$ ions. Alkalinity is an estimate of the ability of water to resist change in $\mathrm{pH}$ upon addition of acid. The alkalinity of tube well water was maximum. This may be due to low water table and lower temperature bringing down the rate of decomposition of salts to a minimum there by increasing the alkalinity. In the present study, some of the samples analyzed had not in the prescribed range as per drinking water quality standard (IS: 10500) and hence require suitable treatments before use. During decomposition of dead plants and living organisms CO is released which results in the addition of the carbonate and bicarbonate, this might be one of the reason for increase in alkalinity value [9]. The alkalinity of water is caused mainly due to $\mathrm{OH}, \mathrm{CO}_{3}, \mathrm{HCO}_{3}$ ions. Alkalinity is an estimate of the ability of water to resist change in $\mathrm{pH}$ upon addition of acid [19]. Maximum Alkalinity is due to increase in bicarbonates in the water [20]. Subjected to two way ANOVA highly significant difference found in between the areas and seasons in alkalinity content. Area $(\mathrm{Fc}=7.64>\mathrm{Ft}=3.43)$, Season $(\mathrm{Fc}=18.47>\mathrm{Ft}=5.31)$. 


\subsection{Hardness}

The minimum value of Hardness was found in tap water of C.W.S. and Balanda Colony in Monsoon i.e. 118.33 $\pm 7.54 \mathrm{mg} / \mathrm{L}$ but maximum hardness found in tube well water of C.W.S. colony in Post Monsoon i.e. $326.69 \pm$ $5.30 \mathrm{mg} / \mathrm{L}$ (Table 1 \& Table 2). Natural sources of hardness principally are limestones which are dissolved by percolating rainwater made acidic by dissolved carbon dioxide. As the value of tube well water exceeds the permissible limit of drinking water quality standard so it needs treatment before use. The high value of hardness may be due to evaporation of water and addition of calcium and magnesium salt by means of plants and living organisms and also due to regular addition of large quantity of sewage and detergent from the nearby residential localities [9]. Calcium or Magnesium salts or both cause almost all Hardness of water [21]. High value of hardness during summer can be attributed to decrease in water volume and increase of rate of evaporation of water [8]. Significantly the river, tub well and tap water differ from each other but no significant difference found between the seasons. Area $(\mathrm{Fc}=6.65>\mathrm{Ft}=3.43)$, Season $(\mathrm{Fc}=0.41<\mathrm{Ft}=5.31)$.

\subsection{Chemical Oxygen Demand (COD)}

The COD value remain minimum in tap water of Balanda colony during Post Monsoon i.e. $30.93 \pm 1.22 \mathrm{mg} / \mathrm{L}$ but the COD value was found to be maximum in tube well water of Jagannath colony i.e. $188 \pm 8 \mathrm{mg} / \mathrm{L}$ (Table 1 \& Table 2). Chemical oxygen demand determines the oxygen required for chemical oxidation of organic matter. COD values convey the amount of dissolved oxidisable organic matter including the non-biodegradable matters present in it. No significant difference found in COD content of River, tub well and tap water but seasonal variation shows slightly insignificant difference when subjected to two way ANOVA. Area $(\mathrm{Fc}=1.12<\mathrm{Ft}=3.43)$, Season $(\mathrm{Fc}=5.31>\mathrm{Ft}=5.30)$.

\subsection{Sulphate}

The minimum sulphate content was found in tap water of Balanda colony during Monsoon i.e. $34.2 \pm 3.97$ mg/L but maximum sulphate was found in tube well water of Jagannath colony i.e. $132 \pm 5.43 \mathrm{mg} / \mathrm{L}$ (Table 1 \& Table 2). Water with higher concentration of sulphate may cause intestinal disorders. Subjected to two way ANOVA sulphate content shows no significant difference in areas as well as in seasons. Area $(\mathrm{Fc}=0.40<\mathrm{Ft}=$ 3.43), Season $(\mathrm{Fc}=0.92<\mathrm{Ft}=5.31)$.

\subsection{Nitrate}

In the present study maximum nitrate content was found in tube well water of Balanda colony i.e. $24.27 \pm 0.61$ $\mathrm{mg} / \mathrm{L}$ and minimum nitrate content was found in Tarini Ghat of river Brahman i.e. $0.47 \pm 0.31 \mathrm{mg} / \mathrm{L}$ (Table 1 \& Table 2). Groundwater levels of nitrate/nitrogen may range up to $20 \mathrm{mg} / \mathrm{L}$ or more, with higher levels characteristically occurring in shallow aquifers beneath areas of extensive development. Nitrate concentration increases due to influx of nitrogen rich flood water that brings about large amount of contaminated sewage water and also nitrate concentration increases due to formation of blooms [9]. Nitrate concentration is found higher in rural areas because of runoff of nitrate rich fertilizers and animal manure into the water supply [22]. Significantly the river, tube well and tap water differ from each other but no significant difference found in between the seasons. Area $(\mathrm{Fc}=5.64>\mathrm{Ft}=3.43)$, Season $(\mathrm{Fc}=0.19<\mathrm{Ft}=5.31)$.

\subsection{Phosphate}

Phosphate is maximum in Pashimeswar Ghat of river Brahmani during Post Monsoon i.e. $423.27 \pm 2.59 \mu \mathrm{g} / \mathrm{L}$ where as it is found minimum in tap water of Jagannath colony in Monsoon i.e. $102.74 \pm 8.94 \mu \mathrm{g} / \mathrm{L}$ (Table 1 \& Table 2). Phosphate occurs in natural waters in low quantity as many aquatic plants absorb and store phosphorous many times their actual immediate needs. The maximum value may be due to the solar radiation, which might have encouraged the biological degradation of the organic matter. Continuous entry of domestic sewage is responsible for increase of phosphate. The high values of phosphate in monsoon are mainly due to rain, surface water runoff, agriculture run off; washer man activity could have also contributed to the inorganic phosphate content [23]. Due to multiplication of plankton concentration of phosphate decrease automatically [9]. No significant difference found in phosphate content in river, tube well and tap water and also in between seasons subjected to two way ANOVA. Area $(\mathrm{Fc}=0.92<\mathrm{Ft}=3.43)$, Season $(\mathrm{Fc}=2.25<\mathrm{Ft}=5.31)$. 


\subsection{Fluoride}

Maximum fluoride content was found in Pashimeswar Ghat of River Brahmani in Monsoon i.e. $664.23 \pm 5.03$ $\mu \mathrm{g} / \mathrm{L}$ and minimum fluoride content was found in tube well water of C.W.S. colony i.e. $250.64 \pm 5.0 \mu \mathrm{g} / \mathrm{L}$ (Table 1 \& Table 2). High concentration of fluoride causes serious health problem. Surface water generally contains less than $0.5 \mu \mathrm{g} / \mathrm{L}$ fluorides. However, when present in much greater concentration, it becomes a pollutant. Areas exist where the fluoride content of water ranges from 1.5 to $6 \mu \mathrm{g} / \mathrm{L}$, for example in the Kurnool district of Andhra Pradesh. Fluoride content is found as significant in river, tube well and tap water but seasonal variation shows no significant difference subjected to two way ANOVA. Area $(\mathrm{Fc}=4.04>\mathrm{Ft}=3.43)$, Season $(\mathrm{FC}=2.90<\mathrm{Ft}=5.31)$.

\subsection{Statistical Analysis}

\subsubsection{Season 1}

In River water, the high positively correlated value was found between the Sodium and conductivity (0.998), sodium and potassium (0.999), chloride and phosphate (1), COD and sulphate (1) and negatively correlated value was found between conductivity and hardness $(-0.998)$, potassium and hardness $(-1)$ at 0.05 level significant but at 0.01 level of significant high negatively correlated value was found between sodium and hardness $(-1)$.

In tube well water, the high positively correlated value was found between the conductivity and DO (0.999), sodium and chloride (0.999), sulphate and fluoride (0.998) and negatively correlated value was found between temperature and chloride (-0.998), DO and TS $(-1)$ at 0.05 level of significant but the negatively correlated value was found between conductivity and TS (-1) at 0.01 level of significant.

In tap water, the high positively correlated value was found between $\mathrm{pH}$ and sulphate (0.999), chloride and COD (1) at 0.05 level of significant and negatively correlated value was found between $\mathrm{pH}$ and sodium ( -0.998$)$, sodium and sulphate $(-1)$ at 0.01 level of significant but at 0.01 level of significant high positively correlated value was found between temperature and nitrate (1), phosphate and fluoride (1) and negatively correlated value was found between hardness and phosphate $(-1)$ and hardness and fluoride $(-1)$.

\subsubsection{Season 2}

In River water, the high positively correlated value was found between the conductivity and chloride (1), conductivity and potassium (0.999), conductivity and nitrate (0.997), conductivity and phosphate (0.998), potassium and chloride (1) and negatively correlated value was found between temperature and DO ( -0.998$)$ at 0.05 level of significant but at 0.01 level of significant high positively correlated value was found between potassium and chloride (1), phosphate and nitrate (1).

In tube well water, the high positively correlated value was found between the conductivity and TS (1), conductivity and sulphate (0.999), temperature and hardness (0.999), sodium and nitrate (1), alkalinity and phosphate (0.998), phosphate and fluoride (0.997) and negatively correlated value was found between conductivity and DO (-0.999), DO and TS (-0.998), DO and chloride $(-0.999)$, DO and sulphate $(-0.998)$ at 0.05 level of significant but at 0.01 level of significant positively correlated value was found between TS and sulphate (1).

In tap water, the high positively correlated value was found between the $\mathrm{pH}$ and COD (0.999), conductivity and chloride (0.999), hardness and sulphate (0.999) at 0.05 level of significant.

\subsection{Water Quality Assessment}

Table 4 represents the water quality index of physicochemical parameters of Monsoon \& post monsoon seasons in river water, tube well water \& tap water respectively.

\subsubsection{River Water}

The overall water quality index in river water, the value ranges from 56 - 57 in season 1 and 43 - 56 in season 2. According to NSF Water Quality Index Legend (Table 3), the quality of river water found as Medium (Table 5). So overall river water is satisfactory.

\subsubsection{Tube Well Water}

The overall water quality index in tube well water, the value ranges from 47 - 50 in season 1 and 44 - 52 in sea- 
Table 3. NSF water quality index.

\begin{tabular}{ccc}
\hline & Water Quality Index Legend & \\
\hline Range & Quality \\
\hline $90-100$ & Excellent \\
$70-90$ & Good \\
$50-70$ & Medium \\
$25-50$ & Bad \\
$0-25$ & Very bad \\
\hline
\end{tabular}

Table 4. Water quality index of physicochemical parameters of monsoon and post monsoon seasons.

\begin{tabular}{ccccccccccc}
\hline Sample & TS (S1) & TS (S2) & DO (S1) & DO (S2) & pH (S1) & pH (S2) & Nitrate (S1) & Nitrate (S2) & Phosphate (S1) & Phosphate (S2) \\
\hline R1 & 20 & 20 & 4 & 4 & 87 & 93 & 96 & 95 & 95 & 90 \\
R2 & 20 & 20 & 5 & 4 & 92 & 92 & 97 & 95 & 94 & 89 \\
R3 & 20 & 20 & 4 & 4 & 92 & 78 & 96 & 64 & 94 & 68 \\
TW1 & 20 & 20 & 4 & 4 & 89 & 89 & 60 & 36 & 92 & 94 \\
TW2 & 34 & 38 & 5 & 5 & 91 & 92 & 38 & 58 & 83 & 94 \\
TW3 & 37 & 20 & 4 & 4 & 93 & 91 & 34 & 33 & 91 & 87 \\
T1 & 20 & 20 & 6 & 6 & 91 & 91 & 96 & 95 & 96 & 94 \\
T2 & 20 & 20 & 6 & 6 & 91 & 89 & 95 & 96 & 96 & 93 \\
T3 & 20 & 20 & 6 & 6 & 88 & 89 & 95 & 96 & 96 & 94 \\
\hline
\end{tabular}

Table 5. Based on 5 factors qualitative study of water between monsoon and post monsoon.

\begin{tabular}{cccc}
\hline Sample & OWQI (S1) & OWQI (S2) & QUALITY \\
R1 & 56 & 56 & MEDIUM \\
R2 & 57 & 56 & MEDIUM \\
R3 & 57 & 43 & MEDIUM \\
TW1 & 49 & 45 & BAD \\
TW2 & 50 & 52 & MEDIUM \\
TW3 & 47 & 44 & BAD \\
T1 & 58 & 57 & MEDIUM \\
T2 & 57 & 57 & MEDIUM \\
T3 & 57 & 57 & MEDIUM \\
\hline
\end{tabular}

OWQI: Overall Water Quality Index, S1: Season 1, S2: Season 2.

son 2. According to NSF Water Quality Index Legend (Table 3), the quality of tube well water of C.W.S. colony and Balanda Colony found Bad (Table 5). But in Jagannath colony it is found medium.

\subsubsection{Tap Water}

The overall water quality index in tap water, the value ranges from 57 - 58 in season 1 and 57 in season 2. According to NSF Water Quality Index Legend (Table 3), the quality of tap water found as Medium (Table 5). So overall tap water is satisfactory.

\section{Conclusion}

The present study assessed the water quality between river water, tap water $\&$ tube well water. Data were compared with surface water quality standards IS: 2296 \& drinking water quality standard IS: 10500 and NSF water quality index in order to classify the quality of water. The parameters were taken for analysis of the water quality; among them two parameters exceed the maximum permissible limit. The physico-chemical data indicate that 
intensive use of waste dumping and the industrial activities have impacted greatly on the quality of drinking water in Talcher region. Sampling stations variations were found significant in Sodium, DO, TS, Alkalinity, Chloride, Hardness, Nitrate and Fluoride contents; the seasonal significant variations were observed in Temperature, COD, Sodium and Alkalinity content. As a conclusion, in this present work we have documented the fact that the region has medium quality drinking water as well as bad quality tube well water in two sampling stations as per NSF water quality index.

\section{Acknowledgements}

This study was supported by the Department of Environmental Sciences, Sambalpur University. The authors are thankful to all the staff of P.G Department of Environmental Sciences for extending all possible and timely cooperation for completion of this research work.

\section{References}

[1] Reza, R. and Singh, G. (2010) Assessment of Heavy Metal Contamination and its Indexing.Approach for River Water. International Journal of Environmental Science and Technology, 7, 785-792. http://dx.doi.org/10.1007/BF03326187

[2] Sangodoyin, A.Y. (1991) Groundwater and Surface Water Pollution by Open Refuse Dump in Ibadan, Nigeria. Journal of Discovery and Innovations, 3, 24-31.

[3] Singh, G. (2004) Status of Water Quality in a Coal Mining Environment-A Case Study in the Jharia Coalfield. Journal of Industrial Pollution Control, 6, 67-69.

[4] Panda, U.C., Sundaray, Rath, S.K., Nayak, P. and Bhatta, D. (2006) Application of Factor and Cluster Analysis for Characterization of River and Estuarine Water System-A Case Study: Mahanadi River (India). Journal of Hydrology, 331, 434- 445. http://dx.doi.org/10.1016/j.jhydrol.2006.05.029

[5] International Commission on Irrigation and Drainage (ICID) (2005) Annual Report: Managing Water for Sustainable Agriculture. Water for Food and Rural Development of ICID, New Delhi.

[6] Reza, R., Jain, M.K. and Singh, G. (2009) Impact of Mining Activities on Surface Water Quality in Angul-Talcher Region of Orissa, India. Mining Engineer's Journal, 10, 22-28.

[7] CMPDI (2005) EIA \& EMP for Open Cast Mine (Jagannath and Ananta) of Mahanadi Coal Limited, Vol. II.

[8] Mahananda, M.R., Mohanty, B.P. and Behera, N.R. (2010) Physico-Chemical Analysis of Ground and Surface Water. IJRRAS, 2, 272-283.

[9] Verma (2012) Water Quality Analysis of an Organically Polluted Lake by Investigating. Different Physical and Chemical Parameters. International Journal of Research in Chemistry and Environment, 2, 105-111.

[10] Alemaw, B.F. and Chaoka, T.R. (2003) A Continental Scale Water Balance Model. A GIS Approach for Southern Africa. Physics and Chemistry of the Earth, 28, 957-966. http://dx.doi.org/10.1016/j.pce.2003.08.040

[11] Kamble, S.M., Kamble, A.H. and Narke, S.Y. (2009) Study of Physico-Chemical Parameters of Ruti Dam, Tq. Ashti, dist. Beed, Maharashtra. Journal of Aquatic Biology, 24, 86-89.

[12] Jena, B., Sudarshana, R. and Chaudhary, S.B. (2003) Studies on Water Quality Parameters around Sagar Island, Sunderbans. Nature Environment and Pollution Technology, 2, 329-332.

[13] Hassenzadeh, R. (2005) Partial Nitration/Annamox as a Biological Process for Treatment of High Strength Nitrogen Wastewater. Master's Thesis, KTH, Stockholm, 5-32.

[14] Pradhan, U.K., Shirodkar, P.V. and Sahu, B.K. (2009) Physicochemical Evaluation of Its Seasonal Changes Using Chemometric Techniques. Current Science, 96, 1203-1209.

[15] Singh, M.R., Asha, G. and Beeteswari, K.H. (2010) Physicochemical Properties of Water Samples from Manipur River System, India. Journal of Applied Sciences and Environmental Management, 14, 85-89.

[16] Adoni, A.D. (1975) Studies on Microbiology of Sagar Lake. PhD Thesis, Sagar University, Sagar.

[17] Hutchinson, G.E. (1957) A Treatise on Limnology, Geography, Physics and Chemistry. John Wiley and Sons, New York.

[18] Sayyed Juned, A. and Bhosle Arjun, B. (2011) Analysis of Chloride, Sodium and Potassium in Groundwater Samples of Nanded City in Mahabharata, India. European Journal of Experimental Biology, 1, 74-82.

[19] Dasgupta Adak, M., Adak, S. and Purohit, K.M. (2002) Studies on Suitability of Surface and Groundwater of Jharbera. Ecology of Polluted Water, 1, 135-142.

[20] Hujare, M.S. (2008) Seasonal Variation of Physico-Chemical Parameters in the Perennial Tank of Talsande, Ma- 
harashtra. Journal of Ecotoxicology and Environmental Monitoring, 18, 233-242.

[21] Nirmala, B., Suresh Kumar, B.V., Suchetan, P.A. and Shet Prakash, M. (2012) Seasonal Variations of PhysicoChemical Characteristics of Ground Water Samples of Mysure City, Karnataka, India. International Research Journal of Environmental Sciences, 1, 43-49.

[22] Tank, S.K. and Chippa, R.C. (2013) Analysis of Water Quality of Halena Blocks in Bharatpur. International Journal of Scientific and Research Publications, 3, 1-6.

[23] Arvindkumar (1995) Some Immunological Aspects of the Freshwater Tropical Wetland of Santhal. Pargana (Bihar) India. Journal of Environmental Pollution, 2, 137-141. 